\title{
Analysis of mutation and promoter methylation of TP53 gene in tumors of the head and neck
}

\author{
Adrian Jarzynski*, Katarzyna Papiernik, Malgorzata Polz-Dacewicz
}

Department of Virology, Medical University of Lublin, ul.Chodzki 1, 20-093, Lublin, Poland

\section{ARTICLE INFO}

Received 08 February 2016

Accepted 14 March 2016

\section{Keywords:}

TP53, mutation, methylation,

head and neck, cancer.

\begin{abstract}
According to current World Health Organization data, worldwide, cancer is second to cardiovascular diseases as the leading cause of death. The p53 protein is a translation product of the TP53 gene, and it has many functions in cells. Indeed, for this, it is commonly called the "guardian of the genome". The aim of this study was to evaluate the prevalence of mutation and methylation in the promoter of the TP53 gene in cells affected with squamous cell carcinoma of the head and neck. The research material consisted of 34 DNA samples isolated from surgically removed tissue fragments of head and neck tumors. In this work, analysis of all samples for the presence of mutations proved negative. This result simultaneously revealed an absence of mutation in the TP53 gene promoter in the analyzed material. However, the detection of changes in the methylation profile status of the promoter of the TP53 gene in the DNA samples revealed the presence of both methylated alleles in $76.5 \%$ of the sample population, while in the remaining $23.5 \%$, methylation was present in only one allele of the studied gene. In our work, we assumed that samples displaying methylation involving two alleles will show greater predisposition to the development of a malignant tumor. The obtained results reveal that despite the lack of mutation in the TP53 gene promoter, its functioning may be impaired by other mechanisms - either epigenetic or environmental.
\end{abstract}

\section{INTRODUCTION}

According to current World Health Organization data, world-wide, cancer is second to cardiovascular diseases as a leading cause of death. This is particularly evident in countries with a high degree of socio-economic development. According to reports from 2012, the number of newly diagnosed cancers in the world has reached incredibly high levels, with over 14 million cases per year [11]. The term "head and neck cancer" encompasses cancers localized in the upper respiratory and digestive tract, including the lips, mouth, pharynx, nasal cavity, sinuses, salivary glands, larynx and ear. Although the clinical course and prognosis depend on the location of these tumors, due to diagnostic and therapeutic similarities, they are assigned to one common group. The vast majority of these cases are epithelial tumors, i.e. $90 \%$ of all head and neck cancers, the remaining $10 \%$ are, i.e.: glandular and lymphatic cancers. Their percentage in all cancers in recent years in Poland ranges from 5.5\% to 6.2\%, which translates into the number of new cases being estimated at 5500 to 6000 cases per year [6].

\footnotetext{
* Corresponding author

e-mail: a.jarzynski87@gmail.com
}

The TP53 gene is located on chromosome 17, and, along with the genes for p63 and p73, belongs to the family of highly conserved genes. TP53 contains 11 exons, but the first does not have the ability to encode the protein sequence. As with other tumor suppressor genes, mutations in this gene is not uncommon. Indeed, it has been estimated that mutations in the TP53 gene occur in $50-70 \%$ of all cancers. A vast majority (98\%) of all mutations is located between the fifth and eighth exon, mainly in conserved regions of the gene. The $\mathrm{p} 53$ protein is a translation product of the TP53 gene - the so-called "guardian of the genome". It is a phosphoprotein with a mass of $53 \mathrm{kD}$, consisting of 393 amino acids [1]. The p53 has several important functions: DNA repair, controlling of apoptosis and inhibition of the transcription of other genes. This protein regulates the cell cycle, due to its ability to block cell division in the G1/S and $\mathrm{G} 2 / \mathrm{M}$ phases. The triggering of $\mathrm{p} 53$ activity primarily occurs as a result of DNA damage. Abnormalities in the structure and function of DNA leads to the activation of a number of kinases and regulatory proteins, such as MDM2 (Mouse double minute 2 homolog), ATM (Ataxia telangiectasia mutated) and ATR (Ataxia telangiectasia 
and Rad3-related protein) [10]. Fundamentally, the MDM2 protein controls the activity of $\mathrm{p} 53$. This protein is capable of forming a heterodimer with $\mathrm{p} 53$, which, in turn, inactivates $\mathrm{p} 53$ and accelerates its ubiquitination. In turn, p300 is also responsible for $\mathrm{p} 53$ ubiquitination, this may play an opposite role - in interacting with $\mathrm{p} 53$, it behaves as a co-activator of transcription (functioning as an acetyltransferase). It is also possible to inhibit apoptosis induced by p53 via the Ras-PI3K-Akt tract, phosphorylating and inactivating caspase 9 . Additional functions of $\mathrm{p} 53$ include the inhibition of angiogenesis and the induction of heat shock. Inhibition of angiogenesis is particularly important during carcinogenesis, because its inhibition in the direct activity of the tumor deprives tumor cells of access to nutrients [9].

\section{AIM}

The aim of this study was to evaluate the prevalence of mutation and methylation in the promoter of TP53 gene, in cells of squamous cell carcinoma of the head and neck. In our work, the presence of the SNP (Single-Nucleotide Polymorphism) mutations was detected in two promoter places: The SNP A/G in the -250 site downstream of the transcription start point; and SNP T/C in the -216 site downstream of the transcription start point. Separately, we also analyzed changes in the profile of the $\mathrm{CpG}$ dinucleotide cytosine methylation of the promoter of gene TP53, in sites -132 and -139 downstream of the transcription start point.

\section{MATERIALS AND METHODS:}

The research material consisted of 34 DNA samples isolated from surgically removed tissue fragments of head and neck tumors. This was derived from patients hospitalized in the Department of Otolaryngology at Mazowiecki Specialist Hospital, in Radom, in 2014. The subsequent isolation of DNA from this tumor tissue was performed using the QIAamp DNA Mini Kit (Qiagen), following manufacturer's instructions. After isolation, the DNA was frozen at $-20^{\circ} \mathrm{C}$ for further analysis.

The detection of SNP in the TP53 promoter was accomplished by amplifying the fragment of gene using the PCR (Polymerase Chain Reaction) method, and applying specific primers as recommended in a publication by Hsieh et al. [4]. Afterwards, restrictive digestion using the $B g l I$ and $B f a l$ enzymes (Thermo Scientific) was conducted. The sequences of primers are: TP53-F: 5'-ACG ATT GAT GAA AGC CTT C - 3 '; TP53-R: 5'-AGC AAC GCA CCG TGT AAG - 3 '. The reaction was performed in a thermocycler LabCycler (SensoQuest), under the following conditions: $94^{\circ} \mathrm{C}-4 \mathrm{~min}$; $94^{\circ} \mathrm{C}-40 \mathrm{sec} ; 50^{\circ} \mathrm{C}-40 \mathrm{sec} ; 72^{\circ} \mathrm{C}-1 \mathrm{~min} ; 72^{\circ} \mathrm{C}-10 \mathrm{~min}$; 45 cycles. The amplified fragment of TP53 gene promoter was 468 bp in length.

For the detection of SNP mutation T/C in the -216 position, $\mathrm{PCR}$ products underwent restrictive digestion using the $B f a I$ enzyme, according to manufacturer's instructions, and then employing electrophoretic separation on a $2 \%$ agarose gel. The products of this activity were further observed under UV. In the absence of mutations, two strands with lengths of $61 \mathrm{bp}$ and $407 \mathrm{bp}$ were visible on the gel. If the test samples revealed the existence of a mutation in -216, there were three strands of $61 \mathrm{bp}, 189 \mathrm{bp}$ and $218 \mathrm{bp}$ in length.

For the detection of SNP mutations $\mathrm{A} / \mathrm{G}$ in the -250 position, PCR products were digested utilizing the restriction enzyme BglI, according to manufacturer's instructions, and, afterwards, underwent an electrophoretic separation on a $2 \%$ agarose gel. In the absence of mutations, strands of $468 \mathrm{bp}$ in length was visible on the gel. If a mutation did occur, there were two strands of $153 \mathrm{bp}$ and $351 \mathrm{bp}$ in length seen on the gel.

The evaluation of the cytosine methylation in the $\mathrm{CpG}$ dinucleotides, within the -132 and -139 positions, was based on the MS-PCR method (Methylo Specific Polymerase Chain Reaction). This technique can determine the methylation status of the gene fragment in a sample that contains even a small amount of genetic material. Compared to classic PCR, in MS-PCR, there is the necessity of performing two parallel reactions by way of employing appropriately designed primer pairs for methylated and unmethylated sequences. These are located in the same place of the tested gene. As DNA polymerase is not able to differentiate between methylated cytosine and unmethylated cytosine, PCR must be preceded by a sodium bisulfate IV reaction (i.e. DNA conversion). Herein, all present unmethylated cytosines in the DNA, deaminate to uracil. Of note, cytosine with the attached methyl rest, is chemically protected against deamination. On the basis of differences in post-modification sequences, primer pairs were designed. For the conversion of test samples, the commercial reagent kit: $\mathrm{CpGenome} \mathrm{Turbo}$ Bisulfite Modification Kit (Millipore), was used, according to manufacturer's instructions. The sequences of primer pairs employed in MS-PCR are:

- for methylated sequence -

M-F: 5'-TTCGGTAGGCGGATTATTTG-3'

M-R: 5'-AAATATCCCCGAAACCCAAC-3'

- for unmethylated sequence -

U-F: 5'-TTGGTAGGTGGATTATTTGTTT-3'

U-R: 5'-CCAATCCAAAAAAACATATCAC-3'

The reaction was carried out in a thermocycler LabCycler (SensoQuest), under the conditions shown in Table 1, using HotStart polymerase (Qiagen). Products from the MS-PCR were electrophoresed on a $2 \%$ agarose gel and observed under UV.

Table 1. MS-PCR conditions

\begin{tabular}{|c|c|c|c|}
\hline Step & Temperature & Time & Cycles \\
\hline Initial denaturation & $95^{\circ} \mathrm{C}$ & $15 \mathrm{~min}$. & - \\
\hline Denaturation & $94^{\circ} \mathrm{C}$ & $30 \mathrm{~s}$ & \multirow{3}{*}{$\begin{array}{c}45 \\
\text { cycles }\end{array}$} \\
\hline Annealing & $\begin{array}{c}58^{\circ} \mathrm{C} \text { for methylated sequences } \\
\text { or } \\
53^{\circ} \mathrm{C} \text { for unmethylated sequences }\end{array}$ & $40 \mathrm{~s}$ & \\
\hline Elongation & $72^{\circ} \mathrm{C}$ & $1 \mathrm{~min}$. & \\
\hline Finish elongation & $72^{\circ} \mathrm{C}$ & $7 \mathrm{~min}$. & - \\
\hline Hold & $4^{\circ} \mathrm{C}$ & - & - \\
\hline
\end{tabular}

\section{RESULTS}

Analysis of all 34 DNA samples for the presence of mutations at SNP, in the -216 site and the -250 site, within the p53 gene promoter, proved negative, This result, simultaneously, revealed an absence of mutation in the p53 gene promoter 
within the analyzed material. However, the detection of changes in the methylation profile status of cytosine in the CpG dinucleotides inside the promoter of the p53 gene in the DNA samples, uncovered the presence of both methylated alleles in $76.5 \%$ of all samples (26 samples), while in the remaining $23.5 \%$ ( 8 samples), methylation was evident in only one allele of the studied gene (Fig. 1).

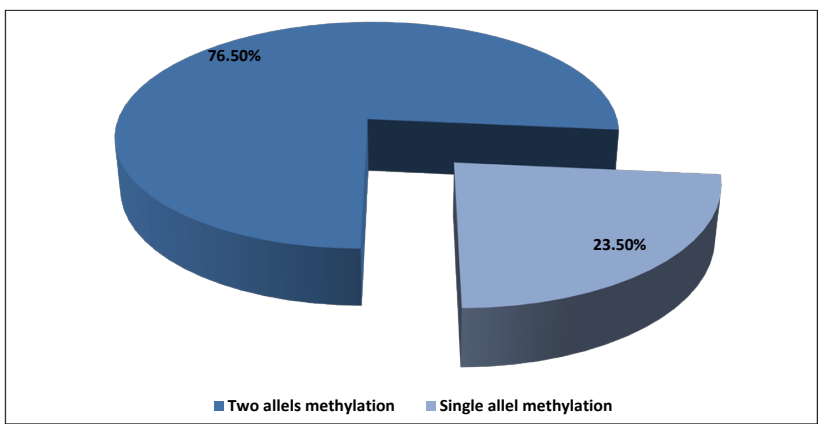

Figure 1. Rating level of promoter methylation of the TP53 gene in the tested samples

\section{DISCUSSION}

Cancers are a major challenge for present day medicine, and today, medical practitioners see a significant, steady increase in the number of malignant tumors with poor clinical prognosis. These include, among others, head and neck cancer. Most cancers located in the head and neck are derived from epithelial tissue. It has been shown that the formation of head and neck cancers largely depends on the molecular changes brought about by external factors. The changes having the greatest impact on the initiation of the carcinogenesis process are mutations in the proto-oncogenes and tumor suppressor genes. Moreover, epigenetic factors are also important factors for cancer development [8].

One of the genes important in cancer progression is TP53. This codes the $\mathrm{p} 53$ protein that is involved in many cellular processes. According to some sources, mutations in the TP53 gene are the most common genetic changes in situations of SCCHN (Squamous Cell Carcinoma of the Head and Neck), and their prevalence in the patient population ranges from $30 \%$ to $70 \%$ [2]. In addition, recent studies indicate that tumors where these mutations have been detected are often resistant to radiation and chemotherapy. This effect greatly reduces the efficiency of the treatment. The reason for these difficulties include mutations in the promoter sequence of the p53 gene. These induce a loss in its basic function, and this brings about a situation wherein cells containing the damaged genetic material are not directed towards the path of apoptosis, thereby allowing carcinogenesis [5]. The correct functioning of p53 may be impaired not only by mutations within the TP53 gene, but also because of mutations in genes responsible for the regulation of its transcription, for example-MDM2. The result of this dysfunction may include a lack of p53 expression in a cell, which, in turn, leads to the deregulation of the cell cycle and the accumulation of negative genetic variation. Furthermore, it appears that, despite the relatively frequent appearance of the mutations in the TP53 gene, the disruption of this protein may be actually attributed to other mechanisms related to the functioning of the cascade of cell regulatory proteins.
Epigenetic changes, i.e. methylation of $\mathrm{CpG}$ dinucleotides in a gene sequence, and the associated acetylation of histones, are also essential to the silencing of p53 transcription [7].

In the analyzed samples, that no positive results regarding the presence of mutations in the promoter of the TP53 gene were evident, may be the outcome of too small a study group. We put forward that DNA analysis of more patients would allow for drawing more accurate conclusions. However, it is also likely that in the study group, there were no significant changes linked to mutations in the promoter region of the TP53 gene predisposing to the disease. It seems that in this case, exogenous factors are more important in the etiology of cancer of the head and neck. Research results confirming the absence of mutation in the test site suggest that during the treatment, these patients will show greater sensitivity to radiotherapy and chemotherapy [8].

In the processes of carcinogenesis, various epigenetic changes, including DNA methylation, are also important. Methylation is a post-replicative enzymatic modification of the genetic material, and it concerns the cytosine in the $\mathrm{CpG}$ dinucleotides. This process is an important part of the gene expression regulation, the maturation and differentiation of cells, the inactivation of the $\mathrm{X}$ chromosome, gene imprinting, and neoplastic transformation. Methylation is particularly important in gene promoter areas where the so-called "CpG islands", are found. These, in turn, are rich in dinucleotides. In situations of tumor growth, hypomethylation of DNA genetic sequences, and the simultaneous maintenance of the hypermethylation of promoter regions of tumor suppressor genes are observed. Due to the presence of such characteristic methylation changes in tumor cells, their analysis provides new opportunities for more effective diagnostics. The research profile of DNA methylation includes relatively simple methods, and the material to be analyzed can be very diverse, for example: blood, saliva, urine and tissue fragments. Currently, there are several known methods for methylation analysis, and the most frequently technique used in this work is MS-PCR [3].

In our work, analysis of changes in the methylation profile of the CpG dinucleotides within the TP53 gene promoter in -139 and -132 , revealed the presence of methylated cytosines in these places. What is more, the vast majority of the tested DNA samples (76.5\% of the patients) showed the presence of methylation of both alleles, while the methylation of a single allele was seen in only $24 \%$ of all patients. It can be assumed that a methylation involving two alleles will show greater predisposition to the development of a malignant tumor. Such would also probably be more severe and less susceptible to the applied therapy than that of patients with a methylated single allele. Hypermethylation of the promoter region of the tumor suppressor gene TP53 is often associated with a decrease in its activity, and can even lead to its silence, and, thus, to the loss of its function. This, in turn, contributes to the process of malignant transformation. Furthermore, the obtained results reveal that, despite the lack of mutation in the TP53 gene promoter, its functioning may be impaired by other mechanisms. These can be epigenetic or environmental. In comparison to mutations, epigenetic changes are reversible, opening doors to the creation of new effective drugs in the treatment of cancer. 


\section{REFERENCE}

1. Bai L., Zhu W.G.: p53: Structure, functions and therapeutic applications, J. Cancer. Mol., 2(4): 141-153, 2006.

2. Blons H., Laurent-Puif P.: TP53 and head and neck neoplasm, Hum. Mutat., 20: 252-257, 2003.

3. Costello J.F., Plass C.: Methylation matters, J. Med. Genet., 38: 285-303, 2001

4. Hsieh Y.Y., Wang J.P., Lin C.S.: Four novel single nucleotide polymorphism within the promoter region of p53 gene and their associations with uterine leiomyoma, Mol. Reprod. Dev., 74:815820, 2007.

5. Lane D.P.: Cancer. P53 guardian of genome, Nature, 358: 15-16, 1992

6. Lis P., Niczyj-Raucy M., Lis M.: The molecular basis of cancer and genetic methods of its diagnosis, Nat. J. (Opole), 44: 92-119, 2011.

7. Nylander D.M, Dabelsteen E., Hall P.A.: The p53 molecule and its prognostic role in squamous cel carcinomas of the head and neck, J. Oral. Pathol. Med., 29 (9): 413-425, 2000.
8. Rusin P., Markiewicz L., Majsterek I.: Genetic predeterminations of head and neck cancer, Post. Hig. Dos., 62: 490-501, 2008.

9. Sznarkowska A., Olszewski R., Zawacka-Pankau J.: Farmakologiczna aktywacja supresora nowotworu, natywnego białka p53 jako obiecująca strategia zwalczania nowotworów, Post. Hig. Med. Dos., 64: 396-407, 2010.

10. Wawryk-Gawda E., Chylińska-Wrzos P., Lis-Sochocka M. Chłapek K., Bulak K., Jędrych M., Jodłowska-Jędrych B.: P53protein in proliferation, repair and apoptosis of cells, Protoplasma, 251 (3): 525-533, 2014.

11. Wojtasiński Z.: Ponad $14 \mathrm{mln}$ nowych zachorowań na nowotwory na świecie, http://naukawpolsce.pap.pl/aktualnosci/news, 402029,ponad14-mln-nowych-zachorowan-na-nowotwory-na-swiecie.html. 